\title{
37 CHILDHOOD INJURY PREVENTION THROUGH COMMUNITY-BASED PARTICIPATORY RESEARCH: A MULTIDIMENSIONAL APPROACH IN THE LOVE AND SAFETY OMURA STUDY IN NAGASAKI, JAPAN
}

doi:10.1136/injuryprev-2012-040590d.37

Deguchi Kimiko, Oono Mikiko, Kitamura Koji, Nishida Yoshifumi. Deguchi Pediatric

Clinic, 3-78 Suwa, Omura, Nagasaki, Japan

Background In Japan the leading cause of death of 1-19 years is unintentional injuries. However, people's awareness of the issue and its preventability remain low.

Purpose To implement a community-based injury prevention programme which citizens, educators, engineers, manufacturers and policy makers work together, recognising one another's strengths.

Methods In Omura, Nagasaki, we conducted a community-based participatory research project, named 'Love \& Safety Omura Study'. We worked with Nagasaki Medical Center and the fire department to collect injury data and identify the causes and characteristics of childhood injury in Omura.

Results Ninety-nine children's injury cases were identified. The number one cause of injury was falls followed by bicycle-related injuries, car crashes, and collisions. Bicycles were most often involved in childhood injuries. Agricultural machinery and twowheeled carts were also related to injuries, reflecting the regional characteristics of Omura. We developed digital content based on the results of data analysis and presented it at a workshop for citizens. Effectiveness of the workshop was evaluated by questionnaires.

Workshop Evaluation Only 65\% of the respondents were aware that unintentional injury is the number one cause of death in children before attending the workshop. All 94\% of the respondents believed that injuries are preventable after attending the workshop, and they successfully indicated preventive actions such as buying childproofing products, pulling the plug on a bathtab, and replacing the rubber seal for a hot water pot, which were introduced in the developed DVD.

Conclusion A collaborative and multidisciplinary approach is key to effective community-based injury prevention. 